\title{
Identifying Success Factors for the Mozilla Project
}

\author{
Robert Viseur ${ }^{1,2}$ \\ ${ }^{1}$ University of Mons (FPMs), Rue de Houdain, 9, B-7000 Mons, Belgium \\ robert.viseur@umons.ac.be \\ ${ }^{2}$ CETIC, Rue des Frères Wright, 29/3, B-6041 Charleroi, Belgium \\ robert.viseuracetic.be
}

\begin{abstract}
The publication of the Netscape source code under free software license and the launch of the Mozilla project constitute a pioneering initiative in the field of free and open source software. However, five years after the publication came years of decline. The market shares rose again after 2004 with the lighter Firefox browser. We propose a case study covering the period from 1998 to 2012. We identify the factors that explain the evolution of the Mozilla project. Our study deepens different success factors identified in the literature. It is based on authors' experience as well as the abundant literature dedicated to the Netscape company and the Mozilla project. It particularly highlights the importance of the source code complexity, its modularity, the responsibility assignment and the existence of an organisational sponsorship.
\end{abstract}

\section{Introduction}

After the launch of the GNU project in 1984 and the emergence of Linux in 1991, the Mozilla project was probably one of the most important events in the field of free and open source software at the end of the nineteenth century (Viseur, 2011). It was a pioneering initiative in the release of proprietary software, while commercial involvement in the development of free and open source software has accelerated over the last ten years (Fitzgerald, 2006). Netscape was the initiator. The company had over $50 \%$ browser market shares, facing up to Microsoft. The challenge was huge. Netscape had to be allowed to maintain its pace of innovation and to sustain its business facing one of the main actors in the software market.

The Netscape decision was inspired by Eric Raymond's essay entitled "The Cathedral and the Bazaar". The author presented his experience with the Fetchmail free software and proposed a set of best practices. "Release early. Release often." is still remembered (Raymond, 2001). However, the Mozilla project was not as smooth sailing. Netscape has seen its market share decline over the last few years. The development team was finally fired in 2003. Success of the project resurfaced in 2004 with the lighter Firefox browser. In December 2012, Firefox had a market share of almost $30 \%$ in Europe (statcounter.com). 
This adventure was studded with victories as well as failures. The implementation of the project needed to find solutions to organisational, legal, technical and economic issues.

Our study is based on the author's knowledge but also on the abundant scientific literature dedicated to the Netscape company and the Mozilla project. Our goal is to identify the success factors for the Mozilla project.

We organised this study into four sections. The first section presents the historical context. The Mozilla project comes from the Netscape browser that dominated the Web browser market between 1993 and 1997. The second section presents success factors that we will use in our case study. The third section develops the case study. The fourth section discusses the results.

\section{Historical Context}

The authorship of the World Wide Web is attributed to CERN (info.cern.ch). Tim Berners-Lee and Robert Cailliau implemented the technical foundations for an open sharing of information on the Internet (Berners-Lee and al., 1994; Ceruzzi, 2012; Grosskurth and Godfrey, 2006). CERN put the system in operation at Christmas 1990. It also published a library ("libwww") and a line mode browser. The merit of making the W3 accessible to a wider audience is often attributed to NCSA (www.ncsa.illinois.edu). In 1993, Marc Andreessen presented the Mosaic graphical Web browser. This one offered a significantly improved user experience and was massively distributed over the network. A part of the Mosaic development team joined Netscape. Marc Andreessen was a co-founder. Netscape gave birth to popular Web browsers. In 1994 Netscape developed its software (clients and servers) for the World Wide Web. Netscape dominated the market until 1997 (Cusumano and Yoffie, 2000).

Microsoft lagged behind the market. However the commercial issue went beyond the Web browser market (Halloul, 2005). Indeed, Microsoft faced the risk that Netscape Navigator and Java would lead to a platform able to replace the Windows operating system (Sebenius, 2002). Microsoft succeeded in about six months to offer a product similar to Netscape. Microsoft relied on a strategy of vertical integration. Internet Explorer was tightly integrated with the Microsoft Windows operating system and came free with it (Wang and al., 2005). Microsoft Windows dominated the operating systems for personal computers. Its users were fairly indifferent for the tool and they tended to use the software installed by default. Some aspects of Microsoft strategy could be criticised. After the failure of a market sharing agreement, Microsoft used its dominant position within its network to prevent Netscape from selling browser with profit (Halloul, 2005). Microsoft imposed Internet Explorer with agreements (for example with computer manufacturers). It organised a policy of systematic incompatibility (format war) (Liotard, 2007). In 1998 Netscape joined legal actions against Microsoft for anti-competitive practices (Descombes, 2002; Halloul, 2005; Krishnamurthy, 2009, Wang and al., 2005). 


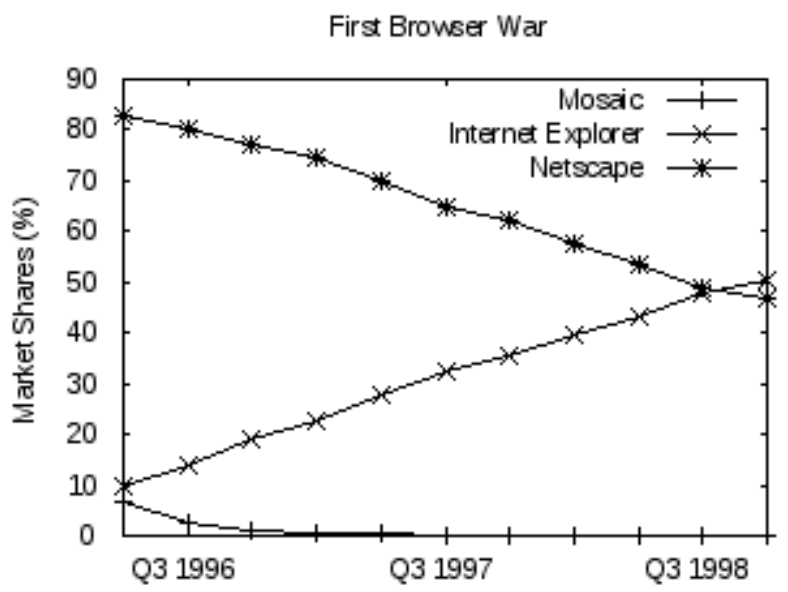

Fig. 1. Netscape market share (first browser war)

The Netscape company announced the release of the source code of Communicator 5 (including the browser) in January 1998. The source code was made available in May 1998. The stakes were high: to allow Netscape to maintain its pace of innovation and sustain its business against a competitor playing a key role in the software industry.

The fifth edition of Netscape did not achieve a commercial future. The sixth edition was released in late 2000. Its instability, its incompatibility with many sites and its heaviness disappointed fans and users, resulting in a significant loss in market share. The number of downloaded copies continued to rise steadily. However, in terms of market share, after a peak of $90 \%$ in mid-1996, the Netscape market share decreased gradually in favour of Microsoft, at a rate of about $1 \%$ per month (Cusumano and Yoffie, 2000; Descombes, 2002). From 18\% in early 2001, the Netscape market share decreased to $12 \%$ in mid-2001. The 7.1 version was released in June 2003 and was based on Mozilla 1.4. It corrected the most troublesome defects. However, the harm was done. Microsoft won the first round of the browser war.

Netscape was acquired by AOL Time Warner in March 1999. In July 2003, AOL Time Warner decided to fire the latest Netscape developers. The development of the Netscape browser was stopped (however several Netscape branded software were sporadically released after 2003). The Mozilla project was then supported by the Mozilla Foundation, established on $15^{\text {th }}$ July 2003. The Firefox browser was released in 2004. Its market share increased regularly, mainly to the detriment of Microsoft Internet Explorer. This growth came to a halt in 2008 with the launch of Google Chrome / Chromium, based on the Webkit open source rendering (or layout) engine. The Mozilla Foundation is absent from Web mobile market and has tried to regain the initiative since 2011 with the launch of the Boot to Gecko project (renamed Firefox OS). 
Table 1. Important milestones of Mozilla project

\begin{tabular}{ll}
\hline Year & Event \\
\hline 1993 & Release of NCSA Mosaic. \\
1994 & Creation of Netscape Communications Corporation. \\
& Release of Netscape Navigator. \\
1995 & Release of Microsoft Internet Explorer. \\
1998 & Launch of Mozilla project. \\
1999 & Acquisition of Netscape by AOL Time Warner. \\
2000 & Release of Netscape 6 based on Mozilla source code. \\
2003 & Death of Netscape. Creation of Mozilla Foundation. \\
2004 & Release of Firefox Web browser. \\
2008 & Release of Google Chrome / Chromium Web browser based on Webkit. \\
2011 & Launch of Boot to Gecko project. \\
\hline
\end{tabular}

Our research covers the period from 1998 (release of Communicator 5 source code and launch of the Mozilla project) to 2012.

\section{Success Factors for Open Source Projects}

Several investigations were devoted to the topic of success factors for open source projects.

Comino, Manenti and Parisi (2007) are concerned about the definition of success. They identified different types of measures: the use of software, the size of the community (or the level of activity, measured for example by the output per contributor) and the technical achievement of the project. Their study leads to three conclusions: first, the restrictive licenses, such as GPL, have a lower probability of reaching a stable or mature release; second, projects dedicated to advanced users have a higher probability of evolving in the development status; and third, the size of the developer community increases the chances of progress up to a certain size, after which this effect decreases. This might be explained by the appearance of coordination problems in large projects.

Fershtman and Gandal (2007) were specifically interested in the output per contributor (lines of code). They concluded that this production is lower if the license is restrictive; it is higher if the software is dedicated to developers (rather than end users) and is lower if the software is written specifically for Linux. The restrictive nature is defined according to three levels (rather than two), with a distinction between permissive licenses (e.g. BSD), license with weak reciprocity (e.g. LGPL) and licenses with strong reciprocity (e.g. GPL).

Stewart, Ammeter and Maruping (2005) focused on the type of the license and the existence of an organisational sponsorship. They showed that a sponsored project became more popular over time, and the popularity of the project (i.e. the success among users) had a positive effect on its vitality (i.e. the success among developers). 
However the impact of the type of the license is not resolved by this study. These results must be seen alongside those of Roberts, Hann and Slaughter (2006) regarding the Apache project. They showed that being paid to contribute is associated with a higher level of contribution on the source code.

Midha and Palvia (2012) used the "cue utilisation theory" (CUT) to determine the factors influencing the success of open source projects. The factors are categorised as extrinsic and intrinsic factors. The extrinsic factors are the type of license, the number of available translations, the size of the user base (since the software exists), the size of the developer base and the responsibility assignment. The intrinsic factors are the complexity and the modularity of the source code. The authors also distinguished two kinds of success: the technical success (i.e. the activity of developers) and the current market success (i.e. the popularity of the project).

They reached following conclusions:

- The technical success does not influence the market success.

- The negative impact of restrictive licenses depends on the status of the project. If we consider the criterion of market success, the negative impact of restrictive licenses only takes place for the first version of the software. It tends to disappear with time. If we consider the criterion of technical success, the negative impact of restrictive licenses does not occur in the early stages of the project but in the following stages. The authors explained this finding by the fact that the license is one of the only pieces of information available to users when the software appears and that the first developers see the restrictive licenses as a protection against the risks of ownership.

- The user base positively influences the market success and the technical success (except in the early stages of the project).

- The number of translations positively influences the success on the market.

- The technical success is positively impacted by the delegation of responsibilities, negatively influenced by the complexity and positively influenced by the modularity.

For our case study, we retain the following factors: the complexity, the modularity, the type of license, the number of available translations, the size of the users' base, the size of the developers' base, the responsibility assignment and the existence of an organisational sponsorship.

These factors are included in the CUT theory. We added the organisational sponsorship (as an extrinsic factor), whose the positive impact is underscored by several studies.

\section{Case Study: The Mozilla Project}

\subsection{The Complexity}

Jamie Zawinski (1999) was a veteran of Netscape and one of the initiators of the Mozilla project. He pointed to the fact that the released code was too complicated and difficult to change. As a result, few people contributed and a complete rewrite of the 
browser was necessary, which delayed the project by six to ten months. This rewrite gave birth to a new rendering engine named Gecko/Raptor.

This need for rewriting was also justified by the objective to propose a rendering engine complying with the Web standards and by an erosion of design, which results in iterative development practices implemented by Netscape (Cusumano, 2007; Reis and Pontin, 2002; van Gurp and Bosh, 2002).

\subsection{The Modularity}

The release of Netscape and the launch of the Mozilla project were accompanied by the provision of valuable development tools. These tools are used to develop the software itself (XUL, Gecko, etc.) and for the organisation of collaborative work (Bugzilla, Tinderbox, etc.) (Reis and Pontin, 2002).

After rewriting the released software, the Mozilla project has been gradually moving towards a stable release. Mozilla 1.4 can be considered as the first fully exploitable release. The Mozilla project has a modular structure. Mozilla technologies can be used by other software and benefit from additional external contributions. The HTML rendering engine, called Gecko, is used as a basis for other browsers like Camino or Galeon. In response to heavy criticisms, Mozilla has been subsequently split into lighter applications. Mozilla Firebird (now Mozilla Firefox) and the Mozilla Thunderbird mail client emerged in 2004.

The extensions (addons.mozilla.org) are considered as an important competitive advantage and mobilise a large community of developers. They can meet very specific needs and attract new users (Krishnamurthy, 2009). In July 2012, more than $85 \%$ of Firefox users used at least one extension, for an average of five extensions by user. These extensions cover features as diverse as ad blocking, video downloading, browser interface customisation and Web page debugging. The Mozilla Foundation also claims more than 25,000 developers for extensions and three billion downloads worldwide.

\subsection{The Type of License}

The creation of a new software license, called Mozilla Public License (MPL), was a part of the project. It was written to regulate the coexistence between the community and the companies. More than 75 third-party modules were used in the browser. Lawyers regard the MPL as original (Montero and al., 2005). It is a license with weak copyleft. It differs notably from the distinction between modified works and wider works. If the first one must remain under MPL, the second one can use a third-party licensed for the original parts. Sun Microsystems was inspired by this license for the Common Development and Distribution License (CDDL). The Open Source Initiative approved MPL 1.1 as well as newer MPL 2.0.

The choice of a software license to cover the new project was a project within the project (Hamerly and Paquin, 1999). The very permissive BSD license did not protect the developers' contributions enough in case of use without compensation by a third party. The GPL was more restrictive (it imposes a conservation and a propagation of 
the license) but it was considered untenable for commercial developers. A new license, called Netscape Public License (NPL), was submitted to developers in March 1998. It seemed very unpopular and was quickly deemed unacceptable by the community because Netscape had been granted special rights. The NPL then became Mozilla Public License (MPL). It was identical to the NPL but skipped over the clause giving the possibility for Netscape to transfer the code licensed under NPL in a product not covered by this license. The source code of the browser subsequently evolved from the original NPL coverage to the MPL coverage (Di Penta and German, 2010). The LGPL and GPL later appeared in the development, in order to address problems of incompatibilities with third-party projects (de Laat, 2005).

\subsection{The Size of the User Base}

The Mozilla project had its roots in the Netscape products and could benefit from the sympathy of a portion of the former user base.

Firefox 1.0 was downloaded two million times in the first two days (Baker, 2005) and surpassed one billion downloads in late July 2009 (Shankland, 2009). Foundation estimated the number of users at 300 million compared to 175 million a year earlier.

\subsection{The Size of the Developer Base}

Recruiting new developers was not easy to start the project. According to Jamie Zawinski (1999), the scope of the project entailed a significant delay before they contributed. As a result, a small change could take several hours. The complexity of the code further aggravated this problem. The efforts of the leading contributors were not rewarded. The contributors expected compensation, such as having the ability to change the commonly used browser version and thus see the effects of their own changes. However, the released sources were not those of the commercially distributed version of the browser (4.x branch). Netscape released a code which lacked many features and was full of bugs. The development capabilities were shared between two versions: the 4.x branch (it underwent several changes, from 4.5 to 4.78 ) and the Mozilla branch. The activity on the proprietary branch did not benefit from the open source branch. The open source development was slowed down by dispersion of resources. The same applied for the commercial branch.

Rewriting the project allowed it to reach its cruising speed. However, changes were then made following the withdrawal of AOL Time Warner, although these were not necessarily visible for an outside observer. The transition was accompanied by a significant decrease in activity of developers and a significant change in the composition of the group of most active developers (Gonzalez-Barahona and al., 2007).

The adoption of Firefox slowed after the release of Google Chrome / Chromium. This was accompanied by tensions within the community, and some departures occurred (Champeau, 2011). The discord focused on the relationship between the contributors in the community and the official structures of the Mozilla project. The fast release cycle that Firefox inaugurated in 2011 in the wake of Chrome (this cycle 
is particularly interesting on a marketing plan) was also the subject of heated debate. The results of this new policy did not seem negative, with a largely preserved stability and faster correction of errors (Khomh and al., 2012).

\subsection{The Responsibility Assignment}

The Mozilla project maintains a centralised decision-making structure. The whole project is managed by a small group of developers (Krishnamurthy, 2005; Mockus and al., 2002; Nurolahzade et al., 2009). This small group delegated tasks and roles. They appointed, in particular, the module owners who are responsible for selecting and implementing changes.

The users can share their report bugs, vote to prioritise them and discuss their resolution. In practice, the development of Mozilla is bug-driven, in other words, led by the bugs (den Besten and Dalle, 2010; Pontin and Reis, 2002). The term "bug" covers defects, enhancements and changes in functionality. The bug reports are encoded, numbered and sorted. If they are confirmed, their correction is planned according to severity and priority. A manager is appointed for each bug. The proposed changes to the source code are finally attached to the bug in the form of patches. These operations are managed through Bugzilla, a Web-based bug tracking system developed in Perl for the needs of the Mozilla project.

The design process is open and User Experience practitioners work in the bug tracker. However, a User Experience director lead the design and "some decisions are made behind the scenes" (Bach and Carroll, 2009). Community can be conservative with design explorations.

The hierarchical organisation of the Mozilla project is the source of frequent disputes but ensures the coherence of development. This structure is perhaps a relic of the past strong involvement of commercial organisation in the development process (as well as the contributions below the expectations after the launch of the project). The history of the project is also that of a transition from commercial to open source development model (Baker, 2005). However, the Mozilla project is distinguished by the large number of contributions made by members at the periphery of the community, which tends to show the relevance of this mode of organisation for a project of this scale (Wang and Carroll, 2011). Taking the votes on the outskirts of the community into account would be low (Dalle and al., 2008).

The gradual shift in the market towards the WebKit open source rendering engine raises questions about the ability of the Mozilla project to accommodate large external contributors.

\subsection{The Organisational Sponsorship}

From May 1998 to July 2003, the Mozilla project was supported by Netscape, owned since March 1999 by AOL Time Warner. Since July 2003 the Mozilla Foundation has overseen the development of the Mozilla project and has received a $\$ 2$ million donation from AOL Time Warner (Baker, 2005). 
Table 2. Organisational sponsorship for Mozilla project

\begin{tabular}{ll}
\hline Period & Sponsor \\
\hline May 1998 - March 1999 & Netscape. \\
March 1999 - July 2003 & Netscape / AOL Time Warner. \\
July 2003 - present & Mozilla Foundation. \\
\hline
\end{tabular}

The Mozilla Foundation derives its income from agreements with commercial search engines. Google accounts for $95 \%$ of its revenues. The Mozilla Foundation (www.mozilla.org) announced that it earned \$52.9 million in 2005 with its browser. In comparison, the revenues amounted to \$2.4 million in 2003 and \$5.8 million in 2004. The Foundation employs 70 employees on a permanent basis. It is dependent on and owes its financial survival of this agreement to Google. Mozilla Foundation and Mozilla Corporation (trading subsidiary) expenditures rose to $\$ 8.2$ million in 2005. Software development accounted for $\$ 6,075,474$ compared to $\$ 768,701$ to $\$ 1,328,353$ for marketing expenses and general administrative expenses.

Support also came from Unix vendors such as IBM, HP and Sun, who put their research and common development capabilities into the Mozilla project and were able to focus on their own needs (West and Gallagher, 2006).

\subsection{Language Translations}

In 2012, Firefox was available in over 70 languages. The Mozilla project ensures long efforts to empower translation (see in particular Mozilla Translator).

\subsection{Technical Success}

The release of Netscape and the launch of the Mozilla project were accompanied by the provision of valuable development tools. These tools are used to develop the software itself (XUL, Gecko, etc.) and for the organisation of the collaborative work (Bugzilla, Tinderbox, etc.) (Baker, 2005; Reis and Pontin, 2002).

After rewriting the code, the Mozilla project has a modular structure. Moreover Mozilla technologies can be used by other software and benefit from additional external contributions. The HTML rendering engine, called Gecko, was used as a basis for other browsers like Camino or Galeon.

In hindsight, it appears that the development tools developed for the Mozilla project sometimes struggled to spread beyond the projects of the Foundation. This is especially true for XULRunner application framework launched in 2007 (Stearn, 2007). XULRunner should bring a runtime environment independent of the operating system for XUL-based applications, a description language for graphical user interfaces based on XML created as part of the Mozilla project. The lack of development environment dedicated to these tools, the gaps in the documentation and the gradual rise of Ajax frameworks help to explain this result in halftone. 
The market success came back in 2004, especially with Firefox. This Firefox breakthrough restarted the browser war that Microsoft won a few years earlier. Several technical elements contributed to the success of Firefox: the protection against popups, the software security (Internet Explorer is regularly criticised in this regard, and viruses and security issues caused inconvenience in the summer of 2004), the tab system, the compliance with Web standards and the ability to create extensions (Baker, 2005; Krishnamurthy, 2009).

\subsection{Market Success}

\section{Promoting the Project}

The Mozilla project was well promoted in 2003. Rewards were offered to the project by newspapers, such as Linux Journal that promoted Mozilla as one of the 10 best Linux products. The marketing efforts of the Mozilla Foundation amplify this comeback.

From a marketing perspective, the Mozilla Foundation became more focused on end users (Baker, 2005; Viseur, 2011). It changed the former site, which contained some major flaws, especially from a "commercial" point of view, which was presented as a site for developers with too much complexity for the normal user. There was too much information which was also poorly structured. For example, multiple versions of the Mozilla site were proposed in footnotes. A beta version could have masked a stable version. However, the end user may not know what is involved in beta (it was the second trial period of a software product before its official publication). Improvements were made with the release of version 1.4 of the browser (mid-2003). The latest stable version was clearly shown (upper left corner of the page). The installation files were classified by an operating system (Linux, Mac and Windows). The information sought by the user was directly accessible. Mozilla also introduced the concept of "product". This is familiar to end users, considers the customer and involves a minimum of strategic thinking. A line of products is highlighted. The end user can choose between the classic Mozilla browser and a new lighter browser called Firebird (now Firefox). This development of a line of products was associated with the development of a brand strategy (Mozilla Application Suite, Thunderbird, Firebird, etc.). The name Firefox is registered as a brand. References (such as awards from magazines and quotes from recognised people) were clearly identified in order to give credibility to the products and to reassure new users attracted to the Web site. Contributors were not neglected. Information intended for testers and developers appeared in a different colour at the bottom of the page. The supported operating systems and tools available were also highlighted. The new initiatives, such as telephone support, sales of CDs and gifts, were pointed across the site.

The Mozilla Foundation subsequently continued its marketing efforts. It launched the Spread Firefox initiative in September 2004 (Baker, 2005). After testing the traditional advertising with the purchase of an advertising page (funded by the community) in the American press, the Mozilla Foundation tested viral marketing in 
2005. FunnyFox site (www.funnyfox.fr) hosted three humourous ads made by the Pozz (www.pozz-agency.com) French communication agency: The Office, The Mobile and The Notebook. The goal was that these three Flash movies were to be widely distributed at the initiative of users and spread all over the Internet. The Foundation then went further in co-creation. This marketing technique for involving customers and users in the design, the development, the promotion or the support of new products and services was applied to the creation of advertisements. Mozilla launched a contest called Firefox Flicks (www.firefoxflicks.com) in late 2005. The goal was to create a marketing campaign to tap into the creative energy of amateur and professional filmmakers in order to present Firefox to a wider audience.

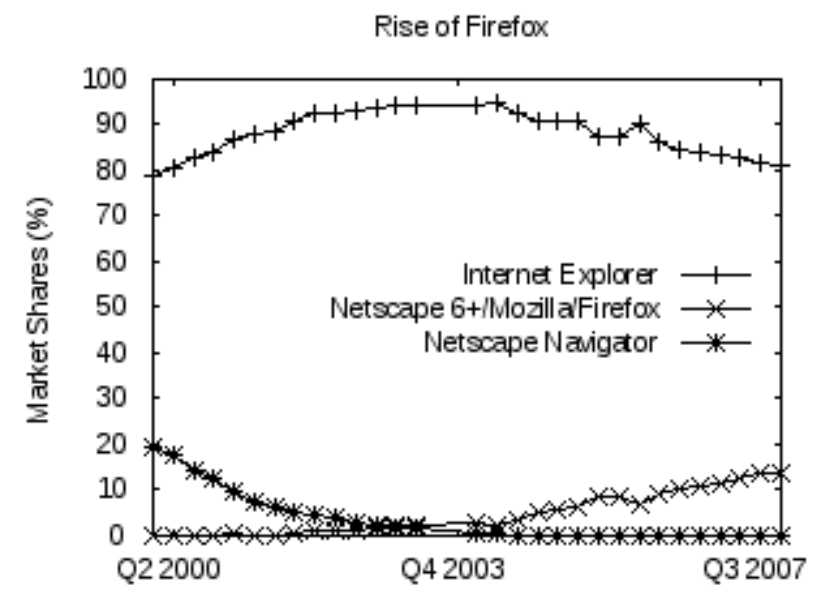

Fig. 2. Firefox market share

The community has also been tapped. Krishnamurthy (2009) identifies three missions supported by the community: the development of the brand, the creation of traffic and the conversion of new users (providing banners, writing positive comments, voting on websites dedicated to software, etc.).

\section{Organisation of the Competitors}

The new browser war may have reached a point in September 2008 with the launch of Google Chrome (www.google.com/chrome). Google was motivated by improving the user experience with rich Internet applications (Corley and Hunsinger, 2011), i.e. applications running in a Web browser with characteristics similar to applications running on the workstation. Google offers this type of product (Youtube, GMail, etc.). Google faced stability and speed problems with existing browsers during testing. Google therefore decided to release its own browser. 


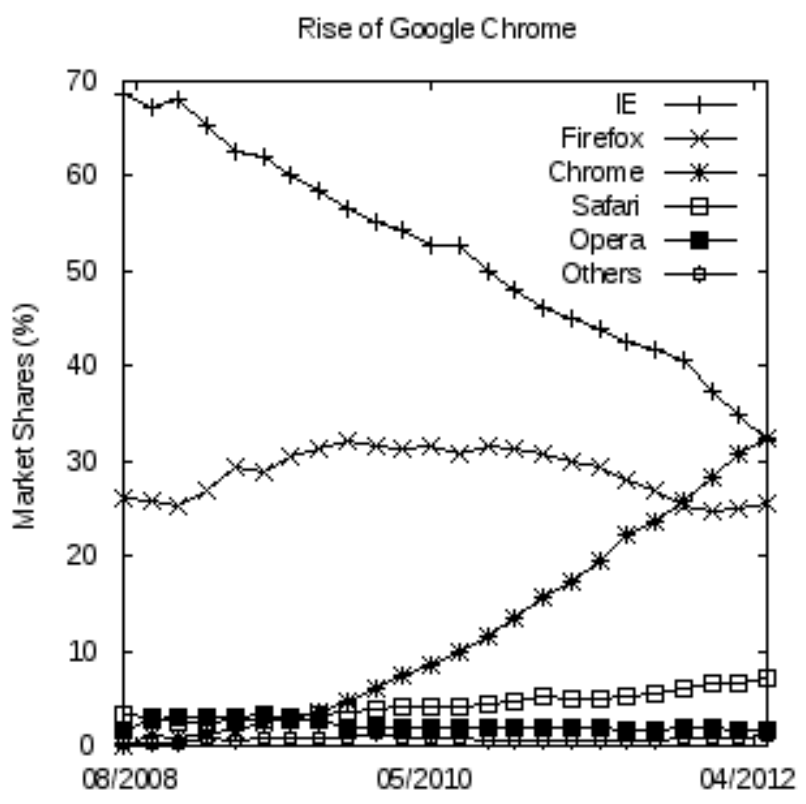

Fig. 3. Google Chrome / Chromium market share

Google Chrome is a browser based on WebKit (webkit.org). WebKit is an open source project which launched in 2005 by Apple for its Safari browser. It is forked from the source code of KHTML, the HTML rendering engine used by Konqueror, the file manager and Web browser combined with the KDE desktop environment (Grosskurth and Godfrey, 2006; Viseur, 2012). Apple was joined on this project by Nokia, Palm and RIM (in practice, Webkit-based browsers dominate the mobile platforms). Chromium is the Chrome free software release (www.chromium.org). The Mozilla ecosystem is particularly fuelled by companies wishing to have a functional browser on platforms other than Microsoft Windows. It is now challenged by a new ecosystem mainly composed of companies that sometimes frontally compete (Google and Apple, for example).

Google Chrome has proven to be fast and stable (process isolation). Google Chrome is frequently offering new versions and its park is quickly renewed through an automatic update system (Baysal and al., 2011). The new product was vigorously promoted by Google, for example by using video spots. It quickly became the third most widely used browser, behind Internet Explorer and Firefox. In practice, the evolution of market shares shows a stabilisation of Firefox browser, a decrease of Internet Explorer and a growth of Google Chrome (gs.statcounter.com). In May 2012, Chrome had a market share of $32.43 \%$, compared to $32.12 \%$ and $25.55 \%$ for Internet Explorer and Firefox respectively. The competition from Chrome tends therefore to erode the market share of the Internet Explorer common competitor.

It raises new questions about the future of the agreement between Google and the Mozilla Foundation, and about the financial sustainability of the Foundation. In the 
long term, the motivations behind the release of Chrome also question the evolution of the Web required by major companies. The border between the Internet and the desktop tends to gradually subside, as between the Web pages and applications.

The competition from Google Chrome / Chromium is also consistent with that of the Webkit rendering engine, especially in mobile systems. Most mobile browsers use Webkit. Mozilla is marginalised on these platforms as they become proportionately more important. The use of tablets and smartphones already becomes, for example, dominant for consulting media Web sites during certain periods of the day (comScore). Mozilla is trying to reposition itself in the market with the Boot to Gecko project, an open operating system for mobile devices.

\section{Discussion and Perspectives}

The influence of intrinsic factors seems to be well emphasised in this case study. The excessive complexity of the released code hindered the start-up of the project and kept potential contributors away, which resulted in a small amount of contributions and a complete rewrite of source code. This suggests the need for thorough preparation before publishing the source code. This rewrite was accompanied by a significant modularisation of source code. The modularity of the browser was enhanced with Firefox that proposed a very popular system of add-ons.

Two external factors stand out: the responsibility assignment and the organisational sponsorship.

The Mozilla project has a centralised decision-making structure and differs from other projects by a module ownership mechanism. It is sometimes a source of tension but this organisation ensures the coherence of the project. The project continues to benefit from many contributions, such as bug reports or corrections ("patches").

The Mozilla Foundation ensures the coherence in the project development and the promotional activity for popularising its software to a wider audience. The impact of the Netscape teams' dissolution also highlighted the impact of the organisation support on the development process of a large-scale and complex project.

In the case of Mozilla, a decision cannot be made regarding the impact of the type of license on the success of the software. However, there was a lot of controversy after the publication of the NPL license illustrated the importance of the license in the eyes of the community and the attention paid to the risks of ownership. Note that the main competitor (Google Chrome / Chromium) is based on a rendering engine that is also covered by a license with weak copyleft.

The technical success depends on the point of view. The Mozilla Firefox project helped to impose open standards for Web site development. One objective of the project was therefore achieved. The market success is undoubtedly linked to the technical success in securing the application or offering modularity ("add-ons"). The success of the Google Chrome / Chromium competitor is also explained by its technical quality and better functioning with websites using technologies for rich clients (e.g. Flash and Ajax). As for disadvantages, the technologies on which the Mozilla browsers are based (e.g. Gecko), or that derived from these technologies (e.g. 
XULRunner), encountered difficulties to export to other projects. It is interesting that most software vendors using an open source rendering engine based their product on Webkit and not on Gecko. Regarding further research on this point, it might be instructive to identify the factors that encourage or discourage the reuse of open source components. The highly centralised project organisation may explain the difficulty to collaborate with other key partners.

The market success came back in 2003 and especially in 2004 with the release of Firefox. Firefox was lighter and modular. It benefited not only from its technical qualities but also from the high number of marketing campaigns. Emphasis is placed on the originality of implementing marketing techniques without a classic commercial structure.

The project now faces a major challenge due to the evolution of the market and the arrival of new competitors. The Web evolves gradually under companies' pressure from a world of documents, developed using standards, to a world of heavier and complex applications (Taivalsaari and Mikkonen, 2011). The release of Google Chrome fits into this context. Another development is the rise of the mobile Web. If the situation on the workstation is currently competitive with balanced market shares between Internet Explorer, Firefox and Chrome, the mobile systems market evolves to a monopoly to the benefit of the Webkit rendering engine that powers most mobile browsers (Hernandez, 2009). The mobile operating systems offer a preinstalled browser and the success of Boot to Gecko will determine the future of the Foundation due to the growing importance of a mobile Web.

\section{References}

Bach, P.M., Carroll, J.M.: FLOSS UX Design: An Analysis of User Experience Design in Firefox and OpenOffice.org. In: Boldyreff, C., Crowston, K., Lundell, B., Wasserman, A.I. (eds.) OSS 2009. IFIP AICT, vol. 299, pp. 237-250. Springer, Heidelberg (2009)

Baker, M.: The Mozilla Project: Past and Future. In: DiBona, C., Stone, M., Cooper, D. (eds.) Open Sources 2.0, The Continuing Evolution. O’Reilly Media (October 2005)

Bar, M., Fogel, K.: Open Source Development with CVS. Paraglyph Press (2003)

Baysal, O., Davis, I., Godfrey, M.W.: A Tale of Two Browsers. In: MSR 2011, May 21-22 (2011)

Berners-Lee, T., Cailliau, R., Luotonen, A., Nielsen, H.F., Secret, A.: The World-Wide Web. Communications of the ACM 37(8), 76-82 (1994)

Ceruzzi, P.E.: Aux origines américaines de l'Internet: projets militaires, intérêts commerciaux, désirs de communauté. Le Temps des médias (18), 15-28 (2012)

Champeau, G.: Mozilla interroge sur son avenir et ménage sa communauté. Numerama, 23 août (2011)

Comino, S., Manenti, F.M., Parisi, M.L.: From planning to mature: On the success of open source projects. Research Policy 36(10), 1575-1586 (2007)

Corley, J.K., Hunsinger, D.S.: Why are People Using Google's Chrome Browser? In: CONISAR Proceedings (2011)

Cusumano, M.A., Yoffie, D.B.: Competing on Internet time. Touchstone (2000)

Cusumano, M.A.: Extreme programming compared with Microsoft-style iterative development. Communications of the ACM 50(10), 15-18 (2007) 
de Laat, P.B.: Copyright or copyleft? An analysis of property regimes for software development. Research Policy 34, 1511-1532 (2005)

Dalle, J.-M., Masmoudi, H., den Besten, M.: Channeling Firefox Developers: Mom and Dad Aren't Happy Yet. In: Russo, B., Damiani, E., Hissam, S., Lundell, B., Succi, G. (eds.) Open Source Development, Communities and Quality. IFIP, vol. 275, pp. 265-271. Springer, Boston (2008)

Dalle, J.-M., den Besten, M.L.: Voting for Bugs in Firefox. In: FLOSS Workshop 2010 (2010)

Descombes, S.: Saga Netscape/Microsoft: histoire d'un renversement. Journal du Net, 23 août (2002)

Di Penta, M., German, D.M.: An Exploratory Study of the Evolution of Software Licensing. In: ICSE 2010, Cap Town, South Africa, May 2-8 (2010)

Elie, F.: Économie du logiciel libre. Eyrolles (2006)

Fitzgerald, B.: The transformation of open source software. MIS Quarterly 30(3), 587-598 (2006)

Gonzalez-Barahona, J.M., Robles, G., Herraiz, I.: Impact of the Creation of the Mozilla Foundation in the Activity of Developers. In: Proceedings of the Fourth International Workshop on Mining Software Repositories (2007)

Grosskurth, A., Godfrey, M.W.: Architecture and evolution of the modern web browser. Preprint submitted to Elsevier Science (2006)

Halloul, R.: Le réseau stratégique et la concurrence illustrés par le cas M/N (Microsoft versus Netscape). Innovations (21) (2005)

Hamerly, J., Paquin, T.: Freeing the Source: The Story of Mozilla. In: Open Sources: Voices from the Open Source Revolution. O'Reilly (January 1999)

Harrison, W.: Eating your Own Dog Food. IEEE Software (May/June 2006)

Hernandez, E.A.: War of Mobile Browsers. Pervasive Computing, 82-85 (2009)

Iansiti, M., MacCormack, A.: Developing products on Internet time. Harvard Business Review, 108-117 (Septembre-Octobre 1997)

Khomh, F., Dhaliwal, T., Zou, Y., Adams, B.: Do faster releases improve software quality? An empirical case study of Mozilla Firefox. In: 9th IEEE Working Conference on Mining Software Repositories (MSR), pp. 179-188 (2012)

Krishnamurthy, S.: About Closed-door Free/Libre/Open Source (FLOSS) Projects: Lessons from the Mozilla Firefox Developer Recruitment Approach. Upgrade 6(3) (June 2005)

Krishnamurthy, S.: CASE: Mozilla vs. Godzilla - The Launch of the Mozilla Firefox Browser. Journal of Interactive Marketing (2009)

Liotard, I.: Les nouvelles facettes de la propriété intellectuelle: stratégies, attaques et menaces. Management \& Sciences Sociales (4), 1-14 (2007)

Midha, V., Palvia, P.: Factors affecting the success of Open Source Software. Journal of Systems and Software 85(4), 895-905 (2012)

Mikkonen, T., Taivalsaari, A.: Apps vs. Open Web: The Battle of the Decade. In: Proceedings of 2nd Workshop Software Eng. for Mobile Application Development (MSE 2011) (2011)

Mockus, A., Fielding, R.T., Herbsleb, J.D.: Two case studies of open source software development: Apache and Mozilla. ACM Transactions on Software Engineering and Methodology 11(3) (July 2002)

Montero, E., Cool, Y., de Patoul, F., De Roy, D., Haouideg, H., Laurent, P.: Les logiciels libres face au droit. Cahier du CRID (25), Bruylant (2005)

Nurolahzade, M., Nasehi, S.M., Khandkar, S.H., Rawal, S.: The role of patch review in software evolution: an analysis of the Mozilla Firefox. In: Proceedings of the Joint International and Annual ERCIM Workshops on Principles of Software Evolution (IWPSE) and Software Evolution (Evol) Workshops, pp. 9-18 (2009) 
Raymond, E.S.: The Cathedral \& the Bazaar (Musings on Linux and Open Source by an Accidental Revolutionary). O'Reilly Media (2001)

Reis, C.R., Pontin de Mattos Fortes R.: An Overview of the Software Engineering Process and Tools in the Mozilla Project. Working paper (February 8, 2002)

Roberts, J.A., Hann, I.-H., Slaughter, S.A.: Understanding the Motivations, Participation, and Performance of Open Source Software Developers: A Longitudinal Study of the Apache Projects. Management Science 52(7), 984-999 (2006)

Sebenius, J.K.: Negociating Lessons from the Browser Wars. MIT Sloan Management Review (Summer 2002)

Shankland, S.: Firefox: 1 billion downloads only part of the story (July 31, 2009), http: //news. cnet.com

Stearn, B.: XULRunner: A New Approach for Developing Rich Internet Applications. IEEE Internet Computing 11(3), 67-73 (2007)

van Gurp, J., Bosch, J.: Design Erosion: Problems \& Causes. Journal of Systems \& Software 61(2), 105-119 (2002)

Viseur, R.: Associer commerce et logiciel libre: étude du couple Netscape / Mozilla. In: 16ème Conférence de l'Association Information et Management, AIM, Saint-Denis (France) (25 mai, 2011)

Viseur, R.: Forks impacts and motivations in free and open source projects. International Journal of Advanced Computer Science and Applications (IJACSA) 3(2) (February 2012)

Wang, J., Carroll, J.M.: Behind Linus's law: A preliminary analysis of open source software peer review practices in Mozilla and Python. In: 2011 International Conference on Collaboration Technologies and Systems (CTS), May 23-27 (2011)

Wang, T., Wu, L., Lin, Z.: The revival of Mozilla in the browser war against Internet Explorer. In: ICEC 2005, pp. 159-166 (2005)

West, J., Gallagher, S.: Patterns of Open Innovation in Open Source Software. In: Chesbrough, H., Vanhaverbeke, W., West, J. (eds.) Open Innovation: Researching a New Paradigm, ch. 5. Oxford University Press, Oxford (2006)

Zawinski, J.: Resignation and postmortem (March 31, 1999), http: / /www . jwz . org 